\title{
Biogas Investment Intention of Large-Scale Pig Farmers Under the Emission Trading System
}

\author{
Wenjie Yao $\dagger$ \\ Zhejiang University of Water Resources and Electric Power, Hangzhou, 310018, China \\ †Corresponding author: rantom_821024@163.com
}

\section{Nat. Env. \& Poll. Tech. Website: www.neptjournal.com \\ Received: 28-08-2019 \\ Revised: 26-09-2019 \\ Accepted: 07-11-2019 \\ Key Words: \\ Emission trading system \\ Large-scale pig farmers \\ Biogas investment intention \\ Pollution treatment}

\begin{abstract}
Based on the field research data of 424 large-scale pig farmers in Zhejiang Province, this paper takes the biogas fermentation as the main adoption behaviour of pollution treatment, and make the quantitative analysis on the biogas investment intention and its influencing factors on large-scale pig farmers under the emission trading system. The research shows that the emission trading system can encourage large-scale pig farmers to adopt biogas fermentation to deal with pollution and make environmental protection investment for waste resources utilization, which mainly depends on the pig breeding scale, the biogas digesters purchased or not, the benefit evaluation of biogas fermentation and the biogas fermentation technology service existed or not, rather than environmental awareness. Therefore, it is feasible to introduce the emission trading system into the agricultural non-point source pollution control with pig breeding pollution as the typical example. For the pig breeding industry, emission trading can be transformed from the traditional redistribution of environmental capacity to the redistribution of production scale.
\end{abstract}

\section{INTRODUCTION}

Because privatization of public resource property right is difficult to operate, it is generally considered unfeasible to implement an emission trading system in the field of agricultural non-point source pollution (Stiglitz 1989). In recent years, more and more scholars (Haiyu 2007, Zhiyong et al. 2012, Weijun et al. 2013, Guangyue et al. 2014, Min et al. 2017) have applied emission trading as an important economic means to control agricultural non-point source pollution, but they have not realized that environmental capacity is not easy to determine because different geographical, meteorological and hydrological conditions have a great impact on pollution migration and transformation. Therefore, the emission trading system in the field of agricultural non-point source pollution cannot be based on environmental capacity allocation, but can only be implemented based on production scale allocation, that is, to control pollution from the source of production. Under the production pattern of large-scale pig breeding, as the main source of agricultural non-point source pollution, the pollution of pig breeding is different from that of chemical fertilizers and pesticides. It can be isolated from the production process and has the special applicability of the emission trading system.

However, can the emission trading system encourage large-scale pig farmers to invest in environmental protection? In the field of industrial point source pollution, some conclusions have been answered in the affirmative. This system enables enterprises to increase investment in environmental protection and invest excessively in pollution treatment technology under the expectation of higher emission trading price (Laffont et al. 1995, Yingde 2012). Moreover, it can encourage enterprises to carry out technological innovation and reduce the unit cost of pollution treatment (Carlson et al. 2000). Of course, some contrary findings should not be ignored. The new environmental protection technology will reduce the marginal cost of pollution treatment of enterprises, leading to a decline in the emission trading price, and reducing the innovation income of enterprises. Therefore, enterprises are not strongly willing to invest in environmental protection under this system (Villegas-Palacio et al. 2009). Especially compared with environmental taxes and fees, if enterprises are short-sighted, the system will not significantly improve their willingness to invest in environmental protection (Milliman et al. 1989, Requate 1995, Requate et al. 2001, Requate et al. 2003).

We are committed to seeking the environmental protection investment intention of large-scale pig farmers under the emission trading system. Based on the field research data of 424 large-scale pig farmers in Zhejiang Province, the biogas fermentation is taken as the main adoption behaviour of pollution treatment, and the quantitative analysis is made on the biogas investment intention and its influencing factors 
of large-scale pig farmers under the emission trading system. We aim to provide a realistic basis and lay an empirical foundation for introducing the emission trading system into the agricultural non-point source pollution control with pig breeding pollution as the typical example, to explore the corresponding analysis framework of property rights trading.

\section{MATERIALS AND METHODS}

\section{Theoretical Framework}

Compared with industrial point source emission trading, emission trading in pig breeding pollution control is essentially a kind of scale right trading. There are three main reasons. First, pig waste comes from a single production form, and the quantity of pollution can be controlled by adjusting the production scale spontaneously. Second, cultivated land is the main carrier of pig waste consumption environment, which has the exclusivity of private use in spatial distribution. Third, the utilization of pig waste as resources has great potential, which can generate economic incentives for environmental protection. Therefore, for the pig breeding industry, emission trading can be transformed from the traditional redistribution of environmental capacity to the redistribution of production scale. This change makes the producers with low cost of emission reduction no longer sell emission rights, but buy scale rights to improve efficiency. Under this system, according to the established environmental capacity standard, namely "the carrying capacity of livestock per 0.067 ha of cultivated land", pig farmers with the ability to recycle wastes will buy scale rights and have strong willingness to invest in environmental protection, and pig farmers who cannot recycle wastes will sell scale rights and have a strong willingness to give up raising pigs when the average cost of production is higher than the average benefit of production.

We take biogas fermentation as the main way to recycle pig waste. The willingness to invest in biogas facilities reflects the extent to which the emission trading system can enable pig farmers to consciously adopt environmental protection. Based on relevant literature (Xinyu 2007, Hao et al. 2008, Bin 2009, Yi et al. 2012) and combined with field investigation, we assume that large-scale pig farmers adopt biogas fermentation behaviour to deal with pollution and have scale economy, or at least no diseconomy of scale, and they have a certain willingness to invest in biogas facilities and are influenced by the eight factors including "large-scale pig farmer from other place or not", "degree of education", "amount of cultivated land", "pig breeding scale", "average annual income of raising pigs", "biogas digesters purchased or not", "benefit evaluation of biogas fermentation" and "Biogas fermentation technology service existed or not".
Generally speaking, if the emission trading system is implemented, pig farmers may be willing to invest in biogas facilities for five reasons. First, due to the lack of cultivated land for pig farmers from other places or the shortage of supporting cultivated land for local pig farmers, a large amount of pig waste cannot be effectively returned to cultivated land. Under environmental regulations, the scale of breeding must be expanded by purchasing scale rights, so as to realize the scale economy effect of pollution treatment. Second, pig farmers with higher education and strong environmental awareness tend to actively respond to the implementation of the emission trading system. Third, pig farmers have higher income or even need to expand the scale of breeding, but diseconomy of scale exists in pollution treatment. Fourth, pig farmers have purchased and built biogas digesters and are encouraged by the scale economy of pollution treatment, or have a higher evaluation of the benefits of biogas fermentation, so they are more responsive to the implementation of emission trading system. Fifth, there are supporting services related to biogas fermentation technology around the pig farm, which can overcome the diseconomy of the scale of pollution treatment.

\section{Model Building}

Under the emission trading system, whether large-scale pig farmers are willing to invest in biogas facilities is a type 0-1 dichotomous dependent variable. Hence we used the binary Logit model to estimate the relevant influencing factors. For the dependent variable "biogas investment intention", a largescale pig farmer who had been willing to invest in biogas facilities was assigned a value of 1 , while a large-scale pig farmer who had been unwilling to invest in biogas facilities was assigned a value of 0 . The specific form of the binary Logit model is as follows:

$$
\log i t\left(I_{i}\right)=\alpha_{0}+\sum_{k=1}^{n} \alpha_{k} X_{k i}+\eta
$$

Here, $I_{i}$ is the probability that the $i$-th large-scale pig farmer is willing to invest in biogas facilities; $X_{k i}$ is the $k$-th influencing factor of the biogas investment intention of the $i$-th large-scale pig farmer; $\alpha_{0}$ and $\alpha_{k}$ are the corresponding regression coefficients; $\eta$ is the random error. We set eight independent variables (Table 1).

\section{RESULTS AND DISCUSSION}

We took large-scale pig farmers as the survey objects. According to the regulations of China Animal Husbandry Yearbook, we took 50 pigs raised at the end of every year as the lower statistical limit of large-scale pig breeding and used the Conditional Value Assessment Method to explore large-scale pig farmers' biogas investment intention under the 
Table 1: Independent variables and their instructions.

\begin{tabular}{|c|c|c|}
\hline Independent Variables & Symbol & Instructions \\
\hline Large-scale pig farmer from another place or not & $\mathrm{X} 1$ & No $=0$, Yes $=1$ \\
\hline Degree of education & $\mathrm{X} 2$ & $\begin{array}{l}\text { Years of academic education: Primary school }=6, \text { Middle school }=9, \\
\text { High school }=12 \text {, Junior college }=15, \text { Undergraduate }=16\end{array}$ \\
\hline Amount of cultivated land & $\mathrm{X} 3$ & A unit of 0.067 hectares \\
\hline Pig breeding scale & $\mathrm{X} 4$ & The amount of pig raised at the end of every year \\
\hline Average annual income of raising pigs & $\mathrm{X} 5$ & Ten thousand Yuan \\
\hline Biogas digesters purchased or not & $\mathrm{X} 6$ & $\mathrm{No}=0, \mathrm{Yes}=1$ \\
\hline Benefit evaluation of biogas fermentation & $\mathrm{X} 7$ & Not very good $=-1$, Almost flat $=0$, Very good $=1$ \\
\hline Biogas fermentation technology service existed or not & $\mathrm{X} 8$ & No $=0$, Yes $=1$ \\
\hline
\end{tabular}

emission trading system. During 2018-2019, we distributed 450 questionnaires to large-scale pig farmers in Hangzhou, Jiaxing, Ningbo, Quzhou and other areas in Zhejiang Province. After information screening and reliability assessment, 424 questionnaires were confirmed to be valid, accounting for $94.22 \%$. The characteristics of survey data are shown in Table 2. The survey results show that: if the emission trading system is implemented, $94.81 \%$ ( 402 households) large-scale pig farmers are willing to invest in biogas facilities, while $5.19 \%$ (22 households) large-scale pig farmers are not; $3.54 \%$ (15) large-scale pig farmers are willing to give up raising pigs completely, while $96.46 \%$ (409) farmers are not; among the large-scale pig farmers (22 households) unwilling to invest in biogas facilities, $68.18 \%$ (15 households) are willing to give up raising pigs completely, while $31.82 \%$ (7 households) are not. Therefore, it is practical to adopt biogas fermentation as the main behaviour of pollution treatment for large-scale pig farmers under the emission trading system.

We used STATA 11 statistical software to estimate the parameters of the binary Logit model with the maximum likelihood estimation method, and further screened the independent variables of the model by the stepwise forward regression method (the standard of P-value of all variables selected was set at 0.100$)$. The results show that the regression equations are well fitted (Table 3).

If the emission trading system is implemented, the larger the pig breeding scale, the biogas digesters are purchased, the lower the benefit evaluation of biogas fermentation, and the biogas fermentation technology service is existed, the stronger the biogas investment intention for large-scale pig farmers will be, and a large-scale pig farmer from other place or not, the amount of cultivated land, the average annual income of raising pigs and the degree of education have no significant impact on large-scale pig farmers' willingness to invest in biogas facilities. A large-scale pig farmer from other place or not, the amount of cultivated land and the average annual income of raising pigs are closely related to the pig breeding scale. With no cultivated land for the large-scale pig farmers from other places, insufficient supporting cultivated land for local farmers, and high average annual income of raising pigs, the expansion of pig breeding scale will be stimulated by purchasing scale rights under the of scale trading system. If the original pollution treatment behaviour exists diseconomy of scale, large-scale pig farmers will be willing to invest in biogas facilities. The biogas fermentation technology service existed is an important factor in the willingness to invest in biogas facilities for large-scale pig farmers and determines the extent to which they respond to the emission trading system. If large-scale pig farmers have already built biogas digesters, they may be motivated by the scale economy of pollution treatment and form behavioural inertia, thus actively responding to the implementation of the emission trading system, but this has nothing to do with the awareness of environmental protection determined by large-scale pig

Table 2: Characteristics of the survey data for large-scale pig farmers.

\begin{tabular}{|c|c|c|c|c|c|c|c|c|}
\hline Independent Variables & $\mathrm{X} 1$ & $\mathrm{X} 2$ & $\mathrm{X} 3$ & $\mathrm{X} 4$ & $\mathrm{X} 5$ & X6 & $\mathrm{X} 7$ & $\mathrm{X} 8$ \\
\hline Maximum & 1 & 16 & 16 & 2800 & 60 & 1 & 1 & 1 \\
\hline Minimum & 0 & 0 & 0 & 50 & 2 & 0 & -1 & 0 \\
\hline Mean & 0.2028 & 7.4387 & 4.3465 & 288.5637 & 7.1105 & 0.6816 & -0.7618 & 0.75 \\
\hline Standard Deviation & 0.4026 & 3.2856 & 2.2729 & 404.9952 & 3.9865 & 0.4664 & 0.4481 & 0.4335 \\
\hline
\end{tabular}


Table 3: Regression results of the binary Logit model for large-scale pig farmers' willingness of investment in biogas facilities under the emissions trading system.

\begin{tabular}{|lllll|}
\hline Independent Variables & Coefficient & \multicolumn{3}{l|}{ Standard Error } \\
\hline X4 & $0.0042^{*}$ & & 0.0022 \\
X6 & $1.5969^{* * *}$ & & 0.4879 & \\
X7 & $-0.7579^{*}$ & & 0.4551 & \\
X8 & & & 0.4681 & \\
Sample Size & 424 & Log likelihood & & -70.6078 \\
LR chi2 & $31.81^{* * * * *}$ & & Pseudo R & 0.1838 \\
\hline
\end{tabular}

Note: $* * *, * *$ and * respectively indicate that the estimated results are significant at the levels of $1 \%, 5 \%$ and $10 \%$. Pearson's test value of model regression is 139.15 ( $\mathrm{P}$ value is 0.997 8), which doesn't reach the significance level of $5 \%$.

farmers' own education level. Of course, some studies have highlighted the significance of environmental awareness. For example, Yi et al. (2012) believe that if pollution emission subsidy is implemented, pig farmers with higher education level are more likely to choose the disposal method of organic manure. Contrary to the theoretical expectation, it is not that the benefit evaluation of biogas fermentation is higher, large-scale pig farmers are willing to invest in biogas facilities under the emission trading system. The reason is likely to be that the scale economy of biogas fermentation as the main adoption behaviour of pollution treatment can only be achieved when the pig breeding scale is expanded to a certain extent. However, under the emission trading system, it not only needs to increase production input but also may have the risk of bidding for scale rights, which may not be able to be borne by many small-scale pig farmers. Here, it can also be verified from the fact that the larger the pig breeding scale, the stronger the biogas investment intention.

\section{CONCLUSION}

The emission trading system can encourage large-scale pig farmers to adopt biogas fermentation to deal with pollution and make environmental protection investment for waste resources utilization. In response to the implementation of the emission trading system, large-scale pig farmers are willing to invest in biogas facilities, mainly depending on the pig breeding scale, the biogas digesters purchased or not, the benefit evaluation of biogas fermentation and the biogas fermentation technology service existed or not, rather than environmental awareness. Therefore, it is feasible to introduce the emission trading system into the agricultural nonpoint source pollution control with pig breeding pollution as the typical example. For the pig breeding industry, emission trading can be transformed from the traditional redistribution of environmental capacity to the redistribution of production scale. However, it is still urgent to investigate and confirm whether the adoption of biogas fermentation by large-scale pig farmers to deal with pollution does not exist diseconomy of scale. Only then can the system design be carried out from five aspects: environmental capacity standard, transaction operation mode, transaction price determination, public participation mode and supporting measures.

\section{REFERENCES}

Bin, L. 2009. Study on determinants of biogas engineering development in large-scale pig farms: The case from Fujian. Fujian Agriculture and Forestry University, Fuzhou, China.

Carlson, C., Burtraw, D., Cropper, M. and Palmer, K.L. 2000. Sulfur dioxide control by electric utilities: What are the gains from trade? Journal of Political Economy, 108(6): 1292-1326.

Guangyue, Z., Hong, Z. and Yiqian W. 2014. Study on emission trading system for agricultural source pollution in Weifang. Environmental Science and Management, 39(10): 24-28.

Haiyu, Z. 2007. Research on the application of tradable emissions to agricultural non-point source pollution. Ecological Economy, 4: 137-139.

Hao, H., Hui, Z. and Danping Y. 2008. An analysis of the determinants in option of biogas technology for swine farmers in Jiangsu Province. China Biogas, 26(5): 21-25.

Laffont, J. J. and Tirole, J. 1995. Pollution permits and environmental innovation. Journal of Public Economics, 62(1-2): 127-140.

Milliman, S. R. and Prince, R. 1989. Firm incentives to promote technological change in pollution control. Journal of Environmental Economics \& Management, 17(3): 247-265.

Min, Q., Jianchun, Z. and Xiaotong, L. 2017. Design and innovation of agricultural non-point source pollution emission trading system. Journal of Northwest A\&F University (Social Science Edition), 17(1): 155-160.

Requate, T. and Unold, W. 2001. On the incentives created by policy instruments to adopt advanced abatement technology if firms are asymmetric. Journal of Institutional \& Theoretical Economics Jite, 157(4): 536-536.

Requate, T. and Unold, W. 2003. Environmental policy incentives to adopt advanced abatement technology: Will the true ranking please stand up? European Economic Review, 47(1): 125-146.

Requate, T. 1995. Incentives to adopt new technologies under different pollution-control policies. International Tax and Public Finance, 2(2): 295-317.

Stiglitz, J. E. 1989. Markets, market failures, and development. American Economic Review, 79(2): 197-203.

Villegas-Palacio, C. and Coria, J. 2009. Taxes, permits, and the adoption of abatement technology under imperfect compliance. Working Papers 
in Economics, 368: 1-29.

Weijun, Y. and Junqing, H. 2013. Research on initial allocation of emission rights of agricultural non-point source pollution based on AHP method a case of the Ashe River basin. Science-Technology and Management, 15(1): 10-13.

Xinyu, P. 2007. Study on biogas technology adoption behaviour and green subsidy policy of livestock farming pollution prevention: Evidence from specialized pig breeding households. Chinese Academy of Agricultural Sciences, Beijing, China.

Yingde, H. 2012. Enterprise environmental protection behaviors under regulation of emission tradable policy based on the data of 223 enterprises from Zhejiang Province. Zhejiang University, Hangzhou, China. Yi, Y., Hui, Z. and Hao H. 2012. Study on the factors affecting breeding farmers' environmental investment in the perspective of pollution subsidies: based on the survey of farmers from Shanghai, Jiangsu and Zhejiang. China Population, Resources and Environment, 22(2): 159-163.

Zhiyong, L., Tao, H. and Yan, W and Xin, H.Z.P.X. 2012. Research on emission trading to be applied to agricultural non-point source pollution control. Environment and Sustainable Development, 37(5): 37-41. 